Strategic Organization, August 2010, Vol. 8, No. 3, Pages 206-229

\title{
Using teaching case studies for management research
}

\author{
Véronique Ambrosini \\ Birmingham Business School \\ University House \\ University of Birmingham \\ Edgbaston \\ Birmingham \\ B15 2TT \\ v.ambrosini@bham.ac.uk \\ Telephone: +44 (0)01214146240
}

\section{Cliff Bowman}

\section{Nardine Collier}

Cranfield School of Management

Cranfield

Bedford

MK43 0AL

Telephone: +44 (0)1234 751122

Fax: +44 (0)1234 750070

cliff.bowman@cranfield.ac.uk

n.collier@cranfield.ac.uk 


\begin{abstract}
Teaching case studies are widely deployed in business schools. They are contextually rich in detail, and students learn by applying and adapting theoretical concepts to specific business situations described in the case. This article proposes a new way to use teaching case studies, as research materials for academics. The article addresses three questions 1) Can teaching cases be used as an alternative to field research? 2) When can teaching case studies be used as secondary data? and 3) How can teaching case studies be used as secondary data? The article concludes that teaching case studies are an unexploited and readily available source of research data, a source which should be considered when going into the field and gathering primary data is not possible.
\end{abstract}

Keywords: Research methods, teaching case study 


\section{Using teaching case studies for management research}

Teaching case studies are widely deployed in business schools. They are contextually rich in detail, and students learn by applying and adapting theoretical concepts to specific business situations described in the case. Students develop judgment and reasoning skills by evaluating different options and focusing on complex problems which usually have no one "right answer" (BIM, 1960; Greiner, et al, 2003). Teaching cases provide a classroom substitute for experience (Garvin, 2007). In this article we propose a new way of using teaching case studies. We argue that teaching case studies could be used as research materials for academics in their quest to advance management knowledge.

While fieldwork would be the preferred option for much management research, there are resource and practical constraints in its implementation and we propose that teaching case studies, which are typically rich in context-specific data, should be considered as a possible and useful additional research resource. While we concentrate here on the use of teaching case studies, we also suggest that these teaching cases should be used as one part of a range of secondary data sources.

This article focuses on tackling the current disconnect between, on the one hand, the research case study, which is a context rich, single sample of one, and on the other hand the widespread use of quantitative methods which are not necessarily able to capture some important phenomena that are not amenable to direct quantification. Hence we propose the use of teaching case studies as a form of research data that can enable the researcher to move between the detail of the single case, and if necessary make comparisons across cases, possibly using quantitative methods. We believe using teaching cases in this way would 
enable progress in theory building and development across a wide range of management topics. We are not the first to suggest that teaching case studies can be used as research data. Larsson (1993) led the way with a persuasive article suggesting how teaching cases and other data could be combined, codified and analysed primarily using statistical methods. Here we extend Larsson's (1993) ideas, and suggest how teaching cases can be first analysed idiographically to capture rich and detailed data and then analysed nomothetically to discern similarities and differences over a large number of teaching cases.

To build our argument the article addresses and is structured around three questions: Can teaching cases be used as an alternative to field research? When can teaching case studies be used as secondary data? And how can teaching case studies be used as secondary data? In the first part of the article, we explain that teaching cases are a form of secondary data and as such, despite some limitations, they could be used as a proxy for field-work. In the second part, we address when teaching case studies are appropriate and how they provide reliable data, as well as when it is practical to use them. In the third part, we deal with issues of methodological trustworthiness, propose a research protocol, and present an illustration of how data could be derived and used. We explain that teaching case studies are a source of secondary data, yet a special source as they were written for teaching purposes. We conclude that they are currently an unexploited and readily available source of research data, which should be considered when going into the field and gathering primary data is not possible.

To be clear at the outset we distinguish between case study research and written teaching case studies. The former is concerned with the research of a contemporary phenomenon; it generally covers fieldwork and relies on multiple sources of evidence in order to achieve 
triangulation (Yin, 1994). The latter are designed for teaching purposes, to help students apply theory to practice in real life situations.

\section{Can teaching cases be an alternative to field research?}

\section{What are teaching case studies?}

Teaching case studies are written by individuals or teams often affiliated with the major case teaching schools (e.g. Harvard, INSEAD, Ivey, IMD). Teaching cases are available direct from case teaching schools, case clearing organizations e.g. the ecch (European Case Clearing House) or journals e.g. North American Case Research Association's Journal.

These teaching case studies endeavour to describe actual business situations, detailing some aspects of organizational life, for example a change programme or the behaviour of a new CEO. They are a description of events and each case is essentially a "study with a sample of one, the 'one n' sample (often being) a situation, an organization or an individual" (Naumes and Naumes, 1999: 13). Teaching cases are written typically using a combination of primary data collection e.g. interviews with managers, and secondary data e.g. press releases, annual reports (David, 2003). Most teaching cases describe a set of circumstances faced by an organization in its real world context (Bussiere, 2005; Mauffette-Leenders et al, 1997), where a decision is required (Lyford et al, 2000), or they are used to help students understand multiple issues in complex situations (Dewing, 1931). They typically include "a chronology of significant events in the organization's development; summaries of important cost, financial and sales data; statements and opinions of employees of the company; and information about the competitors and industry" (Edge and Coleman, 1986: 2). There are different types of teaching cases with different uses (Heath, 2002), but all are designed for use in the classroom to help students develop an appreciation of real life management issues 
and thus are seen as essential in management education (Liang and Wang, 2004), and which help develop a range of learning outcomes and skills, such as knowledge application, analysis, synthesis or evaluation (Banning 2003; Bloom, 1964; Hartman 2006; MauffetteLeenders et al, 1997).

\section{Secondary data}

Young (1989) defines secondary research as activity in which evidence is extracted from sources from various sectors of society, some of which are verbatim or factually based e.g. population censuses, diaries, autobiographies, speeches, and others which are constructed by authors to fulfil a purpose, such as economic records, books, magazines, etc. Teaching case studies can be classified as documents constructed to fulfil a purpose and therefore should be viewed as a secondary research source. The literature is replete with discussions about the associated strengths and weaknesses of secondary research (e.g. Yin, 1994) and an awareness of these weaknesses is important to limit the negative influences they may have on research findings. These advantages and disadvantages must be weighed with the fact that "it is not possible to conduct an unflawed study. Any research method or data source chosen will have inherent flaws" (McGrath, 1982, cited in Klassen and Menor, 2007: 1021). As Miller and Friesen (1977: 256) also state it is "difficult to envisage any one source of information which cannot be subject to some type of systematic perceptual distortion". This is further underlined by Christensen and Carlile (2009) who believe that regardless of whether it is primary or secondary, or qualitative or quantitative, all data are subjective. That said a variety of secondary data sources such as books and newspaper articles (Miller, 1994), shareholder letters (Bettman and Weitz, 1983), annual reports (Arndt and Bigelow, 2000), transcripts of speeches (Barr, 1998) etc. have been successfully used by management researchers, and have allowed them to make valuable contributions to knowledge. 
One of the advantages of teaching case studies is that they are often longitudinal (Miller and Friesen, 1977) and provide insights into the time order in which circumstances change. Having such data available is valuable as time constraints can mean it is not always feasible to go into the field and gather longitudinal primary data (Pitt, 1972). As secondary data, teaching cases can also be used in a meta-analytic manner; their use can allow for the bridging of the nomothetic-idiographic research gap (Larsson, 1993). Bridging this gap means that in analysing multiple teaching case studies one can combine rich, detailed cases with large sample breadth and hence it allows academics to use both quantitative and qualitative methods. Using a combination of research methods also answers Shah and Corley's (2006: 1822) call to "motivate researchers...to use both qualitative and quantitative empirical methods to fully understand their phenomenon of interest, or at least to convince quantitative researchers to draw insights from qualitative research in their area, and vice versa", which would act as a mechanism to build and refine theory.

McKelvey (1997) argues for the blending of qualitative and quantitative methodologies. He puts forward a debate which, in brief, argues that research should advance from the particular to the generalizable. He explains that pursuing only one of these strategies would mean missing the data in the "background forest" because of all the "idiosyncratic trees", and vice versa (McKelvey, 1997). Some authors have successfully blended the two methodologies (Larrson, 1993; Miller and Friesen, 1977). Although as mentioned earlier it has become widely accepted that single case studies give a depth of understanding or detailed accounts of complex phenomena in a way that no other methodology can, their use is often argued against due to the lack of generalizability to a population. The analysis of teaching case studies offers us the opportunity to capture idiosyncrasies and complexity, i.e. detailed and rich data, and 
as we can analyse a large range of teaching case studies we can search for patterns across case contexts and any conclusions we draw can give a wider understanding of a phenomenon. Borrowing McKelvey's (1997) wording, using teaching case studies would enable the researcher to retain and explore the idiosyncratic detail of the trees, while generating an understanding of the background forest. If using this method it should be recognized that there can be problems due to the variability in the way data are collected and interpreted across the different teaching cases, which means that strict selection and coding criteria would be necessary; this is explored in the protocol we present later. If the selection criteria followed are made explicit, then an audit trail can enable others to critique, understand and replicate the research. Following the idiographic analysis of each teaching case study, in order to be able to move to a nomothetic approach it would be important to ensure that the same analysis (coding) structure for each teaching case has been used (this is also developed in the research protocol section).

To conclude, teaching case studies allow us to investigate organizations in some detail, and therefore we have an opportunity to explore the idiosyncratic contexts of individual firms. Fieldwork or ethnographic studies are often advocated because large samples do not highlight idiosyncratic details (Rouse and Daellenbach, 2002), but it is also argued that these methods, while providing depth, do not permit the verification of theories, and that sacrificing validity for richness could detract from the strength of the findings (Levitas and Chi, 2002). We suggest that the strengths of both approaches are to be found in the type of secondary data that teaching cases present. This data bridges the problems identified by 'coarse data' at the more macro level, and 'intrusive methods' at the detailed, micro level (Rousseau and House, 1994). We suggest that teaching cases can lessen these limitations, while harnessing their strengths. As noted earlier, at the micro level as teaching cases have already been written 
from primary or secondary data, they eliminate the need to spend time, money and resources accessing organizations and key individuals, which is often a major deterrent to such research. However, they do give details of an organization's unique resources and context. Comparatively at the macro level, research can then focus on whether patterns can be discerned across teaching cases. This then allows wider conclusions to be drawn, but which are established from real idiosyncratic detail, not proxy variables.

\section{Limitations}

The advantages associated with using secondary data need to be considered together with their disadvantages. Teaching case studies suffer from the same drawbacks as any other secondary data that has been collected by others or gathered for a different purpose (Frankfort-Nachmias and Nachmias, 1996). One of the main limitations is the unreported bias of the author and the potentially incomplete description of the situation (Jennings, 1997). Yet as a counter to this point it could be argued that there are few grounds to suspect the case writer of, at any rate, deliberate bias. Publications on teaching case studies explain that authors are meant to objectively report the facts of a case and that teaching cases are "not supposed to be works of fiction, the literary license invoked by creative writers and film makers is not an option open to case writers" (Swiercz and Ross, 2003: 424). It is "the vehicle by which a chunk of reality is brought into the classroom" (Lawrence, 1953: 215), and can be understood as "describing real business situations that capture the complexity of organizational life, the case method gives participants firsthand experience in the analysis and evaluation of business situations" (Liang and Wang, 2004: 398). Case writers are encouraged not to interpret actions and events: “...you are to act as a reporter, describing as closely as possibly what has occurred. However, you typically have to rely on the recollection of other people, who were either party to the events or at least witnessed them. As a result, there may 
be bias in the way they remember the incidents or situations. The way to overcome this is...to find corroborating evidence concerning the events discussed in the case" (Naumes and Naumes, 1999: 15). Moreover, the case writer is typically not employed by the organization to write the case, i.e. it is therefore less likely to be a hagiography, and if only secondary sources are used no one from the organization is likely to be offered an opportunity to edit the story.

As Miller and Friesen (1977: 256) explain, teaching cases supply published data on a firm, in contrast to "the subjective impressions of an executive of the company. It is more difficult to hide the real situation from a case writer who studies a firm in detail". However, in the writing of teaching case studies certain issues or phenomena may be given more prominence than others as a means to highlight a specific point to students (Liang and Wang, 2004), or some teaching cases may be imprecise or incomplete due to the impossibility of providing exhaustive accounts of past events (Kieser, 1994), or because of the organization's denial of access to some pieces of information. Some teaching cases also tend to be over-rationalistic, CEO-centric and instrumentalist (Liang and Wang, 2004). In addition a single case study may not yield a comprehensive set of information with which to answer a research question. Indeed, even the use of multiple teaching case studies (as dealt with later) may not yield a sufficiently comprehensive data set. This is why, as we explain in the protocol later, teaching cases must be selected on the basis that they contain the appropriate data for answering the research question and they should be used in concert with other secondary data.

Linked to the above matter about the completeness of the accounts of a given case study is the concern that the research outcomes garnered from the investigation of teaching cases could only reproduce the teaching points that the case authors originally sought to project. 
We can suggest, as we discuss later, that the use of multiple teaching cases and teaching notes could facilitate the identification of specific teaching points and the data used to illustrate these points. Dependent on the research question, the emphasis in a case on specific teaching points may have no or little impact on the research. If the research question is related to the teaching points then the data are likely to be valuable and if is unrelated then it could be that what matters is the amalgamation of individual items of information from across various teaching cases. There could also be the concern that teaching case studies tend to be written about organizations which portray extreme examples of an event, process, etc. However, as so often occurs in qualitative and quantitative research, it can be the extremes that are of particular interest, as examples to give evidence of new concepts or theory, or emerging trends or practices (Siggelkow, 2007). As a caveat to this though, the researcher should be aware of this consideration when performing their analysis and especially when generalizing to a larger population or to extant theoretical constructs.

A further possible disadvantage of teaching cases, which also applies to many pieces of secondary data, is that they involve two levels of abstraction (Miller and Friesen, 1977). First the writer of the teaching case interprets the situation when writing the case; the second level occurs when the researcher makes interpretations based on the data in the case, which can then result in distortions of information (Denzin, 1989; Ginsberg, 1984; Reeves et al., 2005). To counter this Miller and Friesen (1977) explain that they believe all sources of information are subject to some degree of systematic perceptual distortion. This is a problem inherent to secondary data. If such data is used, there must be an awareness of the fact that the tacit understanding of the original researcher cannot be accessed (Thorne, 1994). 
Thus far we have made the assumption that there is a reality that case writers can capture and represent. In using teaching case studies as research data we need to agree that "all descriptions of human situations are necessarily partial and incomplete. All of us, including case writers, construct our own version of reality even when we strive to be 'as objective' as possible" (Easton, 1992: 3). Therefore while it is critical to acknowledge reliability issues, it is important to be aware that using teaching cases as research data may not be suitable for researchers adopting a positivist research approach, i.e. who assume that there is a single discernible reality and that data are not changed because they are observed (Guba and Lincoln, 1994). Teaching case studies may be better suited to those adopting an interpretive view, i.e. those researchers arguing that organizations are interpretive systems and that people are constantly involved in interpreting their world (Blaikie, 1993). Hence what matters is to recognize that teaching cases or any other data are socially constructed and to acknowledge this. However this does not suggest that one should not be concerned about the trustworthiness of the data and the findings of the research (Lincoln and Guba, 1985). The caveat to this is that regardless of the advantage or disadvantage of teaching case studies, if they are handled correctly and transparently, in terms of the methodological discussion surrounding their use and the findings they generate, they can be a useful resource.

\section{When can teaching case studies be used as secondary data?}

\section{Appropriateness}

Empirical papers published in top management journals are predominantly quantitative, and many of these studies use secondary data. While this type of research is valuable, many research questions cannot readily be explored using purely quantitative methods. In these situations it may be worth considering the use of teaching case materials. While field work might be the preferred option it is often lengthy, difficult to conduct, costly and fraught with 
many problems in its implementation: interviewing and observation entail a lot of effort, entry has to be negotiated, respondents have to agree to be interviewed, and large quantities of qualitative data need to be processed (Gummesson, 1991; Reeves et al., 2005; Thorne, 1994). Also interviews based on retrospective events may be subject to memory recall problems or key individuals may have left the firm, resulting in the loss of valuable information. Even when qualitative research is performed many researchers have fundamental concerns about $\mathrm{N}=1$ samples. Problems such as these are typical in most forms of management research, and hence it is not surprising that a large proportion of published research is based on quantitative, secondary data. This has been reflected in figures from the Academy of Management Journal (AMJ) which show that only 15 percent of its published work is qualitative, despite the editorial board's belief that the most interesting papers are qualitative (Rynes, 2007). As $A M J$ is considered to be one of the most diverse management journals (publishing organizational behaviour, strategic management, human resources and organization theory papers) this would suggest that this lack of qualitative research concerns most management fields. This type of methodological orthodoxy may stem from a bias against qualitative research (Ashforth, 2005) or because of the difficulties of conducting such research. Over time this may hamper intellectual development or result in the uneven growth of a field; which at the extreme could mean its deterioration (Heugens and Mol, 2005).

To illustrate this point we can use the example of the resource-based view of the firm (RBV). The RBV argues that simultaneously valuable, rare, inimitable and non-substitutable resources can be a source of superior performance. We think the RBV offers a good sub-field to illustrate the benefits of using teaching case studies as research data for two reasons: first, while there is a debate in the RBV literature about the extent to which its basic tenets have been empirically tested (Barney and Arikan, 2001; Barney and Clark, 2007) or not 
(Armstrong and Shimizu, 2007; Bingham and Eisenhardt, 2008; Newbert, 2007, 2008) it is still acknowledged even by the most convinced RBV authors that "while the RBV has emerged as an important and influential theory of persistent superior performance in the strategic management literature, there remain issues at the heart of this theory that have not yet been resolved" (Barney and Arikan, 2001: 174) and there is still a need for further empirical research. Second, we use the RBV because it has wide appeal: "Journals in related fields, such as entrepreneurship, as well as journals in unrelated fields, such as marketing, are also publishing empirical studies in which RBV is tested with increasing regularity" (Newbert, 2007: 140). Indeed one can find the RBV applied to organizational behaviour, economics, international business and human resource management issues (Coff, 1997; Lockett and Thompson, 2001; Peng, 2001; Wright, Dunford et al, 2001). Such a trend suggests that the scholarly community in general has recognized the RBV as an important and informative theoretical perspective. However, it is important to add that the approach we propose could be applied to many other fields, and notably the "soft" (generally organizational behaviour-based) subjects (Burke and Moore, 2003) which need to be explored in detail as they have many idiosyncratic and contingent aspects.

Following Newbert (2007) and Armstrong and Shimizu (2007) we decided to investigate the extant RBV literature to determine what research methods have been used in the past. We reviewed this literature over a 14 year period (1995-2009) across nine leading and newer journals in the USA and Europe which publish strategic management articles. Apart from the reputation of the journal, the choice of journals also reflects a range of methodological orientations: historically US journals have published predominantly quantitative studies, whereas European journals have included a mixture of quantitative and qualitative papers (Heugens and Mol, 2005). 
We reviewed the content of these journals, selecting those papers mentioning the RBV in their title or abstract. These articles were then read to identify whether they reported on the RBV from a conceptual or empirical position. Articles that gave evidence of empirical research were then further reviewed to ascertain whether they had a quantitative or qualitative focus. Our findings are summarized in table 1.

Table 1: Review of RBV articles

\begin{tabular}{|c|c|c|c|c|c|}
\hline & $\begin{array}{l}\text { Number of } \\
\text { RBV } \\
\text { articles }\end{array}$ & $\begin{array}{l}\text { Number of } \\
\text { conceptual } \\
\text { articles }\end{array}$ & $\begin{array}{l}\text { Number of } \\
\text { empirical } \\
\text { articles }\end{array}$ & $\begin{array}{l}\text { Empirical } \\
\text { articles: } \\
\text { Quantitative } \\
\end{array}$ & $\begin{array}{l}\text { Empirical } \\
\text { articles: } \\
\text { Qualitative } \\
\end{array}$ \\
\hline $\begin{array}{l}\text { Strategic } \\
\text { Management } \\
\text { Journal }\end{array}$ & 61 & 19 & 42 & 39 & 3 \\
\hline $\begin{array}{l}\text { Academy of } \\
\text { Management } \\
\text { Journal }\end{array}$ & 18 & $\begin{array}{l}0 \quad \text { (Due to } \\
\text { journal type) }\end{array}$ & 18 & 17 & 1 \\
\hline $\begin{array}{l}\text { Journal of } \\
\text { Management } \\
\text { Studies }\end{array}$ & 20 & 10 & 10 & 7 & 3 \\
\hline $\begin{array}{l}\text { British Journal } \\
\text { of Management }\end{array}$ & 5 & 2 & 3 & 3 & 0 \\
\hline $\begin{array}{l}\text { Administrative } \\
\text { Science } \\
\text { Quarterly } \\
\end{array}$ & 0 & 0 & 0 & 0 & 0 \\
\hline $\begin{array}{l}\text { Journal of } \\
\text { Management }\end{array}$ & 24 & 15 & 9 & 8 & 0 \\
\hline $\begin{array}{l}\text { Human } \\
\text { Relations }\end{array}$ & 2 & 2 & 0 & 0 & 1 \\
\hline $\begin{array}{l}\text { Organization } \\
\text { Studies }\end{array}$ & 3 & 2 & 1 & 0 & 1 \\
\hline $\begin{array}{l}\text { Strategic } \\
\text { Organization }\end{array}$ & 3 & 2 & 1 & 1 & 0 \\
\hline Total & 136 & 52 & 84 & 75 & 9 \\
\hline$\%=$ & & $\begin{array}{l}\text { of all articles } \\
38.24 \%\end{array}$ & $\begin{array}{l}\text { of all articles } \\
61.76 \%\end{array}$ & $\begin{array}{l}\text { of all articles } \\
55.14 \% \\
\text { of all empirical } \\
89.29 \%\end{array}$ & $\begin{array}{l}\text { of all articles } \\
6.62 \% \\
\text { of all empirical } \\
10.71 \%\end{array}$ \\
\hline
\end{tabular}


From table 1 we can see that quantitative studies formed almost 90 percent of all the RBV empirical studies across the nine journals. We can therefore conclude that quantitative methods predominate in RBV research. In the main these studies were based around a series of generated hypotheses, a survey instrument being sent to a sample of $>100$ respondents, statistical testing, and results presented and compared to the hypotheses. This type of empirical investigation is useful as it leads to aggregated responses, indicating possible common trends across an industry for example, but we would suggest these methods do not allow for the rich and detailed investigation necessary to fully understand resources and firm heterogeneity.

Only nine papers (6.62 percent of the total sample, 10.71 percent of the empirical studies) used qualitative empirical research methods: Ambrosini et al, (2007), Boxall and Steeneveld (1999), De La Cruz Déniz-Déniz and De Saá-Pérez (2003), Dutta et al, (2003), Hoffman et al, (2009), McGaughey and Liesch (2002), Maritan (2001), Miller (2003), and Sharma and Vredenburg (1998). Considering that the proportion of qualitative studies published in $A M J$ was 15 percent (Rynes, 2007), we can make the assumption that 10.71 percent reveals an under-representation of qualitative RBV research. We suggest that so few qualitatively based field studies over a 15-year period may be an indication of the difficulties surrounding the execution of such studies. We concur with Heugens and Mol (2005: 126) that "methodological pluralism [is] a better way of addressing the wide range of tremendously interesting organizational and societal problems facing us" and that methodological orthodoxy can lead to the uneven development of a field. Based on the results in table 1 this might be happening with the development of the RBV, and to address this we believe that a method which harnesses the benefits of both qualitative and quantitative approaches could be helpful. 


\section{Reliability}

We have argued above that teaching case studies are a form of secondary data and we propose that as such they should be considered as potential research data. That said we do not argue that it will always be possible or suitable to use teaching case studies. First, they should be used when the researcher has made several checks to ascertain and assess whether the data contained in the case studies are reliable. This is difficult to precisely determine especially as, with any secondary sources, the researcher is unable to 'control' how the data were generated (Cowton, 1998). While the problem cannot be eliminated, measures can be taken to ensure that the data are as credible as possible. For instance, effort can be made to ensure sampling validity, i.e. how the teaching cases are selected. While as a whole teaching cases are attempts to provide a description of a real situation, some are fictitious. Hence we would recommend only using teaching cases that describe real organizations and that these organizations should be named. This would give other researchers the option to check the teaching cases themselves or to conduct further research on the organizations used and triangulate the case data, with their other teaching cases, and other secondary data. Another assessment the researcher needs to make is whether library cases (i.e. cases written from secondary data) rather than field-based cases should be used, as they may add little compared to other forms of secondary data. This judgment will once again be dependent on the research question and also on the availability of other secondary data. That said as we argue that the benefits of using teaching case studies is to get rich and detailed data we would recommend the use of field-based cases.

Another factor in selecting the teaching cases may be to consider the provenance of the teaching cases, i.e. the individuals or institutions that produced them. Generally speaking 
there are no 'rules' guiding the preparation of teaching cases, but some institutions have explicit quality standards; “...to get [a] case published by the North American Case Research Association (NACRA), an independent organization, the work undergoes 'rigorous competition' where professors from other schools pass judgment on the relative merits of the cases", says David Rosenthal, editor of NACRA's...Journal" (Harris, 2003). In Europe, the ecch requires each organization or individual registering teaching cases to certify that it reaches professional quality standards. While this maybe an imprecise criterion it could be used in conjunction with the fact that most academics care about their reputation. We would suggest that where teaching cases are readily available and open to academic scrutiny teaching case writers would not want to compromise their professional credibility by writing poor quality teaching cases. Perhaps even more important as a guarantee of case quality is the reputation of the institution the authors are based in. Peer pressure within highly respected institutions is likely to prevent the publication of poor quality case material.

Triangulation is used to increase the trustworthiness of the data (Denzin and Lincoln, 1994; Yin, 1994). Triangulation could be between multiple teaching cases written about the same organization, and/or it could be from other secondary data sources. By reviewing each teaching case and studying the circumstances it describes, it would be feasible to crossreference each case so as to confirm statements, thus increasing the reliability of the data set. The researcher should also investigate other secondary data sources, such as annual reports or press cuttings, to corroborate the statements made. The decision could be made to remove these statements from further analysis if this is not accomplished. The use of case teaching notes may give further factual evidence to support the case and might also give an external industry context, which could increase confidence in its accuracy. 
We analysed the ecch collection to determine the possibility of reviewing multiple teaching cases held on any one organization. We performed a search on 60 organizations $^{1}$, and discovered that multiple teaching cases had been written on 47 of them (see table 2). This indicates that there are a significant number of teaching cases written on individual organizations to be able to undertake some form of corroboration. We believe that these reliability steps should be taken to assess the trustworthiness of the data in the teaching case studies, and from this the researcher should determine whether the case can be considered. We would recommend that teaching cases should "pass" the majority of these reliability tests. Not only does the use of multiple teaching cases improve reliability, but it is also necessary to ensure a variety of information and different perspectives on an organization. Multiple teaching case studies also permit different perspectives to be garnered, first in the organization to be explored, for example the teaching case may be written from a financial, marketing or strategic angle, and second in the types of information used to write the teaching cases, which will bring more depth to the data available. Finally, just as when one performs primary research into an organization, the scope of a research question is unlikely to be directed to understanding the entire organization, but is more likely to be focused on comprehending a particular aspect or process. 
Table 2: Examples of multiple cases held on organizations (based on the ecch collection, as of October 2008)

\begin{tabular}{|c|c|}
\hline Organization & Number of cases \\
\hline Airbus & 23 \\
\hline Amazon & 31 \\
\hline AMD & 19 \\
\hline Amgen & 11 \\
\hline AT\&T & 2 \\
\hline Avis & 3 \\
\hline $\mathrm{BBH}$ & 3 \\
\hline Bellsouth & 4 \\
\hline Benetton & 18 \\
\hline Benihana & 4 \\
\hline Black and Decker & 10 \\
\hline Black Water Rafting & 3 \\
\hline British Petroleum & 36 \\
\hline BSKYB & 8 \\
\hline Bunge & 3 \\
\hline Burger King & 10 \\
\hline Canon & 15 \\
\hline Cemex & 14 \\
\hline Cendant & 3 \\
\hline Dell & 62 \\
\hline Deutsche Bank & 12 \\
\hline Disney & 91 \\
\hline Easyjet & 12 \\
\hline Ebay & 50 \\
\hline Fedex & 22 \\
\hline First Direct & 4 \\
\hline Ford & 72 \\
\hline General Electric & 59 \\
\hline Google & 59 \\
\hline Grasim & 3 \\
\hline Hallmark & 2 \\
\hline Harley-Davidson & 24 \\
\hline Hynix & 2 \\
\hline Hyundai & 16 \\
\hline JD Hall and Sons & 2 \\
\hline Nando's & 2 \\
\hline Nike & 11 \\
\hline Ogilvy and Mather & 4 \\
\hline Olympic Games & 9 \\
\hline Philips & 53 \\
\hline Porsche & 16 \\
\hline Renault and Nissan & 47 \\
\hline Ryan air & 13 \\
\hline Schneider & 8 \\
\hline SKF & 9 \\
\hline Virgin Atlantic & 6 \\
\hline Washington Opera & 2 \\
\hline
\end{tabular}




\section{Practicalities}

It is important to highlight some of the main benefits of using secondary data, notably time, time management (Hakim, 1982) and cost. Researchers using such data can work when they want, and to their own schedule, as they do not depend on participants or special conditions. Furthermore teaching case studies are inexpensive (Larsson, 1993). As secondary data already exists it is generally less expensive than primary data (Cowton, 1998), and with regard to teaching case studies many inspection copies can be obtained for free by faculty members. In any case the cost is negligible when compared with going into the field. This means that researchers can carry out detailed empirical research even when they have limited funds.

\section{How can teaching case studies be used as secondary data?}

\section{Methodological trustworthiness}

In order to better appreciate how teaching cases could be used as secondary data we conducted a review of the literature to look for precedents of usage. We found four studies in major journals whose authors have used teaching case studies as research data and not just as illustrations: Miller and Friesen (1977), Larsson (1993), Larsson and Finkelstein (1999) and Larsson and Lubatkin (2001). The latter three studies followed similar research protocols. This mainly consisted of selecting secondary cases fitting the remit of the research question, and having a detailed coding schema that was used by multiple raters to draw conclusions and analyse the data. The use of multiple raters is advocated to increase reliability (Gibbert, Ruigrok and Wicki, 2008). The authors all performed a wide search of many different types of secondary data, including teaching cases, as they did not wish to prematurely exclude data "based on arbitrary a priori judgments about their methodological rigor, publication status or age" (Larsson and Finkelstein, 1999: 9). 
Miller and Friesen (1977) used what they defined as 'undisguised cases' in their research, primarily employing teaching case studies from the Harvard Case Collection, in conjunction with cases published in Fortune and in textbooks. The protocol they established was very similar to that employed in the studies cited above, but with the addition that they sent statements selected from the cases to top executives of the companies in question to check for validity of fact, and then generated hypotheses and performed statistical tests (Miller and Friesen, 1977). Thus there are precedents for using teaching cases in research, and being explicit about the steps taken in any research gives clarity to the reader, allows for replication of the study and increases its reliability.

Our approach shares similarities with Larsson's (1993) article, in which he advocates the use of the case survey method. However there are some differences between our article and his work; some of our ideas add to Larsson's (1993) research, whereas other parts of it build upon his ideas, and take it forward in new directions. The similarities between our two articles begin at a fundamental level, in that it is an approach which attempts to transcend the nomothetic-idiographic gap. One of the differences between our two approaches is that Larsson's (1993) case survey method takes case studies and via a coding schema quantifies them for generalization through statistical analysis. Although when moving from idiographic to nomothetic analysis we have the potential to quantify the data, quantification is to be used essentially to categorize and summarize the qualitative findings (Langley, 1989). It is only when breadth and complexity has been captured that we would look for patterns, differences etc. (Chatman, 1989), which is a slightly different approach to Larsson's (1993) study, which sought statistical generalization. Also unlike Larsson (1993) we are not attempting to code the degree of a particular variable, for example the level of turbulence in an environment, but 
instead, for example what resources a firm possesses, their interactions and their creation. Larsson (1993) himself admits that his quantifying method sacrifices the depth of data and simplifies complex phenomena, whereas our method aims to view this rich data in a new way; we wish to retain the qualitative nature of the data. The aim of our approach to the analysis of cases is to discover new, hard to elicit knowledge about complex phenomena.

This has related implications for other differences which exist between our articles. Larsson (1993) advocates using any type of search, for example via computer or experts, to garner any type of data: from research case study publications, dissertations and conference papers to teaching case studies, business literature and unpublished sources, as long as they are relevant to the research question. We agree that all sources included in the data set should be relevant to the research question; however, our focus is strictly on teaching case studies as an untapped data source. As such we suggest that the researchers should perform an initial quality control check by only taking teaching case studies from recognized case clearing establishments. Finally Larsson's (1993) sample size is large, which is also necessary because the results are subject to statistical analysis, whereas because we endeavour to retain the qualitative richness of the teaching cases our sample size would vary, but is likely to be less than 100 cases.

It is important to give evidence of methodological trustworthiness, i.e. of reliability, and to show that the research can be audited. Based on these prior studies and the work of Yin and Heald (1975) and Jauch et al, (1980), who proposed protocols on how to select and analyse published data, we suggest that teaching case studies should be content analysed: "content analysis refers to the means of summarizing, standardizing, and comparing...already existing data" (Smith, 1975: 218) as it is a method that is amenable to replication (Frankfort- 
Nachmias and Nachmias, 1996). If the content analysis protocols are clear and explicit other interested researchers could replicate the research, methodological trustworthiness would be enhanced as it lets the researcher present a "clear chain of evidence", and the procedures are made transparent (Gibbert et al, 2008: 1468). As explained earlier, as teaching cases can be used in both nomothetic and idiographic ways we suggest a replication analytic design should be followed. This means that an individual case is treated as an independent experiment, with the aim being to support or contrast the emerging findings (Yin, 1984) and having multiple cases would allow for comparison or confirmation of what has been identified (Yin, 1994). As we have mentioned previously in studying multiple teaching case studies to answer a research question, we suggest that the researcher will need to take relevant facts from one teaching case and then confirm them with facts in another case, or another form of data from a secondary source. Also, depending on the research questions researchers can decide on either using emergent or a priori coding, and on factual coding, i.e. coding of actions, facts, concrete phenomena and/or on interpretive coding, i.e. coding of more abstract issues and concerns, such as causes and effects of an event or motives (Hoque, 2006). Thus teaching cases could be used either for theory testing or theory building (Eisenhardt, 1989).

While it is important to recognize any validity and reliability issues that may emerge from using teaching case studies, we also need to acknowledge that whatever research method is used researchers will make certain tradeoffs (Ginsberg, 1984; McGrath, 1981; Weick, 1979), and such issues, if made explicit, should not be a deterrent to conducting research that would allow the development of the management field. With this in mind we think that teaching case studies are an appropriate way of collecting data. In particular using teaching cases not only allows the researcher to access the details of individual organizations, but by selecting 
across a number of teaching cases generalizable patterns can be explored to support or test theoretical constructs.

\section{A research protocol}

Here we suggest a research protocol that could be used in the content analysis of teaching case studies. Clearly as with any type of analysis this protocol would need to be adapted to each specific research question. It consists of six steps:

1. Ascertain the variables of interest from the research question. In our illustration below these variables are firm success and firm resources.

2. Identify the type of teaching case studies needed to access the variables of interest. Some case collections organize teaching cases by topic, and search terms can be used to interrogate the collection, or they may be selected on the basis of time periods or industries. Only teaching case studies that explicitly name the organization should be included. Dependent upon the research question being studied different types of teaching case studies may be more or less suitable. For example, some researchers may only consider those teaching cases which include an industry-level discussion, whereas others may want the detail of the activities of a certain department or function, further still some researchers could require evidence of particular actions and may not distinguish between the level at which the teaching case is written. Hence the selection of teaching case studies is ultimately contingent on the topic of interest.

3. Define a coding schema. In the illustration given later, the purpose of the research was to identify valuable, rare, inimitable and non-substitutable resources, so the schema listed candidates for resource status, to then identify whether they were valuable, In other words we decided the types of information we would need to collect from the teaching cases. Here we chose a priori coding rather than emergent coding. We also determined how this 
information would be recorded and represented. Again dependent on the research questions a researcher may wish to utilize different coding mechanisms, for example the Strauss and Corbin (1998) coding process, or Huff and Jenkins (2002) causal mapping techniques.

4. Run a pilot sample of the teaching case studies through the coding schema to establish whether it can deliver the information required, and to ensure that all the raters understand the coding schema in the same way.

5. Use multiple raters to improve the validity and reliability of the results generated from the teaching cases (Gibbert et al, 2008). The raters should independently read each case study, recording detailed notes. This should include a stage where all the details identified concerning an organization are cross-referenced. Detailed notes are then used to generate associations common to the research question. At this time the raters should compare their associations and discuss, to a conclusion, any identified discrepancies. If necessary the original teaching case studies should be returned to, in order to verify points. This process should be concluded with one final set of output data for each organization. In our example that follows, three raters independently worked through all the teaching case studies held on a particular organization. We aimed for unanimity, but on the few occasions where this was not achieved we settled for majority agreement (Reynolds and Gutman, 1988). Levels of inter-rater reliability can vary depending on the simplicity of the coding schema and the raters' experience. It is also likely that it can be increased where the raters' have experience of working with each other and if they have extensive knowledge of the research topic. At this point levels of disagreement, and then overall consensus, should be reported. While triangulation could occur at an earlier stage, in the example that follows, this occurred when our notes were checked against other secondary sources. We suggest that if data cannot be validated they should be omitted from the 
study. In some instances, it may be feasible to check with the case writers themselves. Where feasible and where the information is critical to the enquiry we suggest this should be done. As explained earlier at this stage we are studying single organizations, we are at the idiographic stage of the process so we are looking for the detailed idiosyncracies of the phenomena and therefore we are concerned with analytic generalization (Yin, 1994). As a principle, in any research, one should only make claims about findings as far as the data and the research question permits.

6. Nomothetically analyse the findings from a range of teaching cases. Once a large number of teaching cases have been analysed there is an option to add a quantitative element to the overall study, permitting an element of external validity through cross-case analysis (Eisenhardt, 1989). It would then be feasible to look across teaching cases and apply a second level of coding. This stage could involve quantitative analysis of the coded second level data and an examination of whether it was possible to derive, for instance, patterns across a number of teaching cases. This approach (bar the last step) is illustrated below.

\section{An illustration of how teaching case studies could be used as research data}

One of our anonymous reviewers made the following comment, which captures the essence of the role teaching cases can play in strategy and organization research: "The paper addresses a fundamental dilemma at the intersection of strategy and organizations. In order to explore the most interesting questions in our field, we often need intimate knowledge of an organization, knowledge that is difficult to obtain. In order to discern general patterns, however, we often need a large number of data points. How can we obtain many data points and know each data point well? Teaching cases may be a source of intimate knowledge on a large number of organizations". We endorse this view. We suggest that the primary research 
value of teaching cases would result from the identification of detailed 'data points' from many organizations, and the categorization and analysis of these aggregated data. As explained in the protocol the first steps involve the analysis of a single firm, using available case study materials, then, depending on the research question, we proceed to analyse subsequent cases. In the example that follows, we begin by examining one firm, easyJet, which reveals some interesting issues in the RBV, and we indicate how the analysis of further cases would enable us to make some more generalizable insights.

RBV proponents argue that simultaneously valuable, rare, inimitable and non-substitutable (VRIN) resources can be a source of superior performance and are the basis for sustained competitive advantage (Barney, 1991). Unique resources can be acquired through luck (Barney, 1986), insightful procurement (Makadok, 2001), organic development (Eisenhardt and Martin, 2000), or they may be a consequence of an alliance (Seabright et al, 1992) or acquisition (Saxton and Dollinger, 2004).

The RBV is essentially about firm differences. The VRIN criteria can be used to assess whether a resource is likely to be a source of sustainable competitive advantage. The RBV emphasizes that strategically important, but subtle and detailed differences are likely to explain performance variations between competing firms, it stresses the need to isolate idiosyncratic sources of advantage (Rouse and Daellenbach, 1999), and recognizes that the value of a firm's resources can only be assessed in the firm's specific context (Barney, 2001, Helfat and Peteraf, 2003).

Wernerfelt (1995) argues that resources tend to be regarded as an 'amorphous heap', which current quantitative approaches do not permit the researcher to unpack, and Rouse and 
Daellenbach (1999) suggest that large sample observations will not identify resources that lead to sustained advantages. The RBV suffers from a high level of abstraction (Priem and Butler, 2001), hence there is a need for further research, and we might conclude that studies which allow for the identification of sources of advantage and that incorporate firm context may help advance the RBV, especially as creating suitable proxies for a large sample is a challenge which, as yet, has not been adequately addressed (Armstrong and Shimizu, 2007).

We now present an illustrative example of our approach. We selected a popular and top selling case: easyJet, a short haul low cost airline based in the UK. The case matches the choice criteria we established earlier (named organization, various teaching cases and other secondary sources available etc.). Following the protocol outlined above we first analysed the 12 teaching case studies available on easyJet with the aim of identifying its RBV resources. For the period of the teaching case studies easyJet was the fastest growing UK airline, and its profit performance outstripped all rival UK-based airlines. The teaching cases explain that the basic easyJet business model was replicated from Southwest Airlines: easyJet's founder, Stelios Hajiannou "was very impressed with Southwest and decided to adopt the same model for his airline, which was to be based in Europe" (Regani and Dutta, 2003: 3). In this respect it could be argued that the resources which underpinned Southwest's success did not comply with the full VRIN criteria, insofar as Southwest's business model could be imitated. However, an awareness of the sources of Southwest's success is no guarantee that a rival airline could replicate these resources (Rivkin, 2000).

From the teaching cases we identified easyJet's practices. While Stelios was inspired by Southwest, he also "added his own twist to the Southwest concept" (Rogers and Kumar, 2000: 2). For example, easyJet did not use travel agents, its reservations could only be made 
via direct bookings, it did not issue tickets, or give "free" food to passengers. easyJet flew brand new planes and heavily relied on PR and brand promotion: "Stelios' tongue-in-cheek advertising, [and] positioning easyJet as the David against industry's Goliaths was highly effective" (Doz and Balchandani, 2003: 9). One of the results of these marketing activities was brand awareness. It was not only understood by its customers as being cheap, but as cheap and cheerful, and it had a reputation of being customer focused and responsive. Stelios made it a priority to achieve high levels of customer satisfaction and to compete on service. These practices, which stem from Stelios's vision for how he wanted the company to be, seem to reflect a cost focus, but one which did not compromise customer service levels, as a 'way of life' for easyJet.

The next step was for one researcher to identify the particular set of resources and practices that seemed to account for easyJet's competitive performance. This was accomplished by tracking easyJet's activities and assets and examining the elements and practices reported in the teaching case studies, to ascertain how they connected and interacted, and to show evidence of how these resources were created. The various pieces of information that were gathered from the individual teaching case studies were cross-referenced for corroboration in the other teaching cases, and with data held in other sources, in this instance annual reports. Once finalized the overarching and evidence-trailed data set was passed to the two other members of the research team as per the protocol. As an outcome of these discussions a final data set was constructed depicting the interacting elements in easyJet's business model.

From this process, it was possible to draw a number of conclusions regarding easyJet's success. The most striking finding was the rather mundane nature of the individual practices that easyJet deployed. What seemed clear was that many of the practices appeared to be 
imitable: the demand-based fare structure, eliminating travel agents' commissions, encouraging internet booking, a paperless reservation system, using only Boeing 737s, eliminating business class, operating only short-haul point-to-point, charging for in-flight food, getting flight attendants to clean the plane, outsourcing non-core activities (e.g. checkin, baggage handling), a no-frills HQ based at Luton, itself a cheaper airport, no secretaries etc. However, easyJet was delivering high customer satisfaction and in terms of its relative performance, it was a very profitable company. So what was generating the rents?

The teaching cases also revealed some aspects of the company that might be inimitable: the corporate culture, Stelios's image, popularity and his ability to get in the news, but it was difficult to identify direct connections between these inimitable differences and the firm's financial performance. This suggests that the source of easyJet's advantage was not any one individual resource. What delivered advantage was the combination or configuration of these 'mundane' and imitable practices; value was created through the interactions between them, rather than the practices in isolation. For instance the rapid turnaround time that allowed planes to fly for more hours than its competitors was possible because of a combination of paperless reservations, no seat allocation, which facilitated rapid check-in and incentivized early passenger arrival at the gate, all planes being the same model so that there were no crew or facility delays as every aspect of the operation was fully interchangeable, no meals which removed the need for loading of catering suppliers, and finally flying short haul point-topoint, so there was quicker refuelling, turnaround and check-in. Lower costs were further achieved by the combination of the outsourcing of baggage handling, commission only reservation agents, multi-tasking flight attendants, electronic payment (no cheque handling), initial finance from Stelios's father and no travel agents' commissions. 
Taken individually, each element of these combinations is probably imitable, therefore it cannot qualify as a VRIN resource; what might be difficult to replicate, however, is the configuration of practices combined with a culture that encourages staff to operate these practices effectively, and to continually look for additional ways to reduce costs. This culture was created by Stelios over time: "you build the legend slowly, bit by bit, battle by battle. You talk about it, and then you get together and have fun. I believe that work should be fun" (Rogers and Kumar, 2000: 8).

This highlights how critical the role of Stelios Hajiannou is to the success of easyJet. He initially had access to low cost capital to start the firm, he had a clear vision about what he wanted to create, and the energy and charisma to achieve his dream. He acted to create the inimitable configuration of practices that made up the airline. The low cost vision became part of the culture at easyJet. These in tandem resulted in cost focus becoming a way of life for employees, not just an espoused aim. Standardization across all of easyJet's planes and operations also meant that repetition happened everywhere, reducing the need for training and maintenance, and increasing economies of scale, another source of advantage.

Clearly, any analysis can only reflect the information included in the teaching cases and other available sources, and therefore there is no guarantee that we have captured all the critical aspects of easyJet. The complexity of many organizations and the unobservable nature of some resources would preclude any claims of a comprehensive analysis of firm success. However, what has been identified from the teaching case material are plausible explanations for easyJet's success, and from the teaching cases it was apparent that competitors were unable to replicate easyJet's system, although based itself on the Southwest model, 
suggesting that while some of its features might be replicable, either ambiguous resources are required, or the particular configuration of practices is difficult to replicate.

These conclusions are in line with Dierickx and Cool's (1989) argument that the success of an organization is based on a complex pattern of interlinked, context-specific activities, and that a specific element cannot be isolated as the sole source of success. A similar point was also made by Rivkin (2000: 824) whose study explored why some firms' "strategies yield superior returns even after many of their critical ingredients are adopted by competitors" (2000: 824) or by Levitas and Chi (2002) who point out that revealing a unique resource does not equate to replicating it, due to causal ambiguity (Lippman and Rumelt, 1982), tight fit among activities, i.e. consistency between activities, reinforcing activities and optimization of activities (Porter, 1996), complexity (Rivkin, 2000), or tacitness (Nonaka, 1991). This added to the fact that practices are formed from the very particular historical and current combination of organizational features (people, structures, technologies etc.) means they are difficult to replicate (Tranfield and Smith, 1998). In summary, because activities are context dependent their effectiveness "is not measured by what is achieved in principle but by what is achieved in practice; this generally means that the routines might be declared effective in some specific contexts, but perhaps not in others" (Cohen et al, 1996: 662). We could surmise that Stelios understood the Southwest 'recipe' but adapted it ("added his own twist") and "moved ahead of the Southwest business model" (Doz and Balchandani, 2003: 8). He did not 'blindly' try to copy the model, but modified it to fit to his vision and the European context.

Feldman and Pentland's (2003) distinction between ostensive and performative routines might also be useful here. They explain that an organizational routine is formed of two elements: the ostensive aspect, which is the structure or abstract understanding of the routine, 
and the performative aspect, which is the actual performance of the routine (Feldman and Pentland, 2003). The performative resource would be the specific asset, in its firm context. Ostensive resources would be abstractions derived from a range of performative resources. These ostensive categorizations might focus on some generic feature shared across a number of performative resources, enabling comparisons across firms, and industries, but still allowing others to evaluate the nature of these categorizations. Thus the ostensive 'recipe' (Feldman and Pentland, 2003) from Southwest could be readily comprehended. The enacting of the recipe, the specific manifestation of it (the performative aspect) inevitably introduces variations that reflect those involved, and the context and timing of these developments. Over time additional sources of variability evolve, some which are valuable, and maybe inimitable, others which may be less valuable, or may even be sources of disadvantage (Leonard-Barton, 1992). The cases reveal that the Southwest model was copied by other airlines which subsequently failed, e.g. Go!. Thus either aspects of the Southwest model were not appropriately recreated in these failed attempts, or there were elements of the recipe that were not captured in the ostensive description. It may be that subtle aspects of culture, leadership and shared values are critical to success, and that these were incorporated in an emergent, path-dependent way in both Southwest and easyJet, but failed to emerge in rival attempts to establish a low cost airline. It could be that Stelios's ease of access to capital provided the breathing space to enable these critical elements of the recipe to develop.

The illustration confirms that it might be difficult to understand how success is generated by looking at one element in isolation; it is necessary to understand the 'co-located' bundle of resources (Teece, 1986). The teaching case analyses revealed that the sources of easyJet's success consisted in the interactions between a large number of imitable practices; the configuration of practices is difficult to imitate, not the practices themselves. We believe that 
these complex causes of success are most likely to be revealed through the detailed and forensic analysis of teaching cases.

\section{Discussion}

The above is an illustration of how teaching case studies could be used to access the details of an individual firm. The next goal would be to analyse a larger number of organizations and explore patterns across a number of teaching cases. In analysing organizations through multiple teaching case studies we would be able to combine rich, detailed cases with large sample breadth, i.e. as we argued earlier, it would allow us to bridge micro and macro domains and also allow us to contain different levels of analysis within the same study. For instance, at the micro level the entrepreneur's actions could be a unit of analysis, but by comparing those actions across firms and finding firm patterns, the unit of analysis may become the firm. Then by looking across firms within the same industry we could make comparisons across industries. In our illustration the research focus was the identification of easyJet's sources of advantage. However, a range of other issues that would allow for the further refinement of the RBV could also be addressed.

We could for instance explore whether within an industry firms had similar resource configurations where resource interactions produce valuable synergies. We could also address resource creation processes, looking to explore the extent to which these processes were common across competing firms, or we could investigate whether resources result from deliberate management interventions, or from more emergent processes, or indeed, from luck (Barney, 1986). Teaching cases could provide examples of isolating mechanisms, which could enable research into which mechanisms occur most frequently, and in which contexts, and pertaining to which classes of resource. These approaches may also help in addressing 
Newbert's (2008: 746) request that we should explore how managers can first identify their resources and then "in turn seek out and exploit (those) that might not only contribute to their firms' competitive position, but also fit with their idiosyncratic business models".

These investigations would be performed at a detailed level with data from each firm, building from the bottom up to explore cross-firm patterns. This approach would likely reveal the contextual nature of resources, i.e. a specific resource adds value in this firm, within this industry, and at this point in time. By building up from these context-specific resources we should be better able to judge whether it is meaningful to generalize resource types, resource interactions and resource configurations across firms, or across industries. Thus the contextual nature of resource value, captured in the 'industry effect' problem (Armstrong and Shimizu, 2007), can be addressed and appropriate judgments made. The extent to which firm resource stocks can be compared or patterns can be found is largely a function of the research question being investigated. For example, if we were interested in exploring whether knowledge resources are more or less critical in different industry contexts we would need to find ways of categorizing resources. The fine-grained, bottom-up approach we suggest would require judgments about the similarity of resources, required for comparisons across industries, to be explicit so others can assess their appropriateness.

We have illustrated how an analysis of a single firm using teaching case study data can offer insights that can help us reflect on current theory, in this instance the RBV. It is important to note though that the easyJet case was an illustration to show how the protocol could work. Our argument is not meant to be about the RBV, it is a methodological argument. It shows that when access to field data is not possible teaching cases are a way of gathering detailed data, and that if data is gathered from a large number of cases one could explore differences 
or move from specifics to general patterns. The protocol we set out is workable and, we believe it should help researchers avoid some of the problems when using teaching cases as secondary data sources. However, case study data is used widely across many fields of enquiry e.g. medicine, anthropology, sociology, psychology, and other methodologies have been developed to extract valuable insights from specific case situations. For instance in sociology Ragin (1989) has proposed a method based on the binary logic of Boolean algebra to maximize the number of comparisons that can be made from only a limited use of cases. These methodologies may be equally applicable to the analysis of teaching case studies as they are to other case material. Once we have established that teaching case studies are legitimate research data then we would encourage researchers to explore any suitable techniques that, say, combine qualitative and quantitative methods, that have been successfully deployed in other fields. Data from the teaching cases could be used as any other cases to either motivate a research question, provide inspiration or illustrate a conceptual contribution (Siggelkow, 2007).

\section{Conclusion}

In this article we asked whether teaching case studies could be used as research data. We argued that teaching case studies are a currently unexploited and readily available stock of research data and that they present an opportunity to confront some of the empirical challenges faced by many theories. We illustrated our argument using the RBV. However, this approach could be applied in any field in need of empirical support and/or which needed to be explored in detail because of its idiosyncratic and contingent aspects e.g. recruitment and selection, customer relationship marketing, entrepreneurship, supply chain management. 
We explained that the credibility of the data could be enhanced by choosing teaching cases written by academics from reputable institutions and by triangulating the data by using multiple teaching cases or other sources. We also explained that the teaching cases should be analysed in a way that is amenable to replication, i.e. content analysis. Of course, there are a number of other approaches that could possibly be used to achieve the purpose at hand. For instance, if time, cost and access were not an issue, researchers should ideally go into the field and gather primary data. Teaching case studies enable us to combine the benefits of both qualitative (fine-grained detail) and quantitative (generalizable from the data after qualitative review) methods in a cost effective and time efficient manner. Using teaching cases might allow the more intangible elements of theories to be investigated; those that are not amenable to quantification. This should then add empirical fine-grained data helping us to refine theory.

Hence we propose that teaching cases should be considered when either qualitative fieldwork cannot be conducted, and/or when quantitative methods are not a viable option in the inquiry, or to supplement any qualitative or quantitative investigation While gathering primary data, rather than relying on secondary data, is likely to generate more insights, using secondary sources may be useful for exploratory research to develop theory, rather than for theory testing. Interrogating teaching cases may offer us insights that have yet to be developed in the literature and that may be worth exploring in future research, either conceptually and/or via primary research. Once the analysis of a large number of teaching case studies has been conducted, it should be possible to group and then analyse them within and across industries, compare size of firms etc. In turn these findings could be compared with results using other methods where available. 
This article extended the previous work undertaken by Larsson (1993). We concentrated on teaching case studies as an unexploited data source, and explained how they could be utilized in conjunction with other secondary data sources, and how the data could retain its qualitative richness through comparisons, and the identification of patterns. Teaching case studies are a source of secondary data which are special insofar they have been created for a pedagogic rather than research purpose, and hence our article considered the issues in utilizing them as research data, and recommended a protocol that should help to maximize the value of these cases as research data. We believe that using teaching case studies would allow researchers to provide better insights into their theories, and hopefully better theory could be of use to managers in their day-to-day practice. 


\section{Note}

${ }^{1}$ The 60 cases were selected in ascending order from a list of "Top 100 selling case studies". 


\section{References}

Ambrosini, V., Bowman, C. and Burton-Taylor, S. (2007) 'Inter-Team Coordination Activities as a Source of Customer Satisfaction', Human Relations, 60: 59-98.

Armstrong, C. and Shimizu, K. (2007) 'A Review of Approaches to Empirical Research on the Resource-Based View of the Firm', Journal of Management, 33: 959-986.

Arndt, M. and Bigelow, B. (2000) 'Presenting Structural Innovation in an Institutional Environment: Hospitals' Use of Impression Management', Administrative Science Quarterly, 45: 494-522.

Ashforth, B. (2005) 'Becoming Vanilla Pudding: How We Undermine Our Passion For Research', Journal of Management Inquiry, 14: 400-403.

Banning, J. (2003) 'The Effect of the Case Method on Tolerance for Ambiguity', Journal of Management Education, 27: 556-567.

Barney, J. (1986) 'Strategic Factor Markets: Expectations, Luck, and Business Strategy', Management Science, 32: 1231-1241.

Barney, J. (1991) 'Firm Resources and Sustained Competitive Advantage', Journal of Management, 17: 99-120.

Barney, J. (2001) 'Resource-Based Theories of competitive Advantage: A Ten Year Retrospective on the resource-Based View', Journal of Management, 27: 643-650.

Barney, J. and Arikan, A. (2001) 'The Resource-Based View: Origins and Implications', in M. Hitt, R. Freeman and J. Harrison (eds) The Blackwell Handbook of Strategic Management. Oxford: Blackwell.

Barney, J. and Clark, D. (2007) Resource Based Theory: Creating and Sustaining Competitive Advantage. Oxford: Oxford University Press.

Barr, P. (1998) 'Adapting to Unfamiliar Environmental Events: A Look at the Evolution of Interpretation and Its Role in Strategic Change', Organization Science, 9: 644-669. 
Bettman, J. and Weitz, B. (1983) 'Attributions in the Board Room: Causal Reasoning in Corporate Annual Reports', Administrative Science Quarterly, 28: 165-183.

BIM (British Institute of Management) (1960) Case Study Practice. Bedford: The Sidney Press.

Bingham, C. and Eisenhardt, K. (2008) 'Position, Leverage and Opportunity: A Typology of Strategic Logics Linking Resources with Competitive Advantage', Managerial and Decision Economics, 29: 241-256.

Blaikie, N. (1993) Approaches to Social Enquiry. Cambridge: Policy Press.

Bloom, B. S. (1964) Stability and Change in Human Characteristics. New York: Wiley.

Boxall, P. and Steeneveld, M. (1999) 'Human Resource Strategy and Competitive Advantage: A Longitudinal Study of Engineering Consultancies', Journal of Management Studies, 36: 443-464.

Burke, L. and Moore, J. (2003) 'A Perennial Dilemma in OB Education: Engaging the Traditional Student', Academy of Management Learning and Education, 2: 37-52.

Bussière, D. (2005) 'Forensic Marketing: The Use of the Historical Method in a Capstone Marketing Course', Journal of Marketing Education, 27: 61-67.

Chatman, J. A. (1989) 'Improving Interactional Organizational Research: A Model of Person Organization Fit', Academy of Management Review, 14: 333- 349.

Christensen, C. and Carlile, P. (2009) 'Course Research: Using the Case Method to Build and Teach Management Theory', Academy of Management Learning and Education, 8: 240-251.

Coff, R. (1997) 'Human Assets and Management Dilemmas: Coping with Hazards on the Road to Resource-Based Theory', Academy of Management Review, 22: 374-402.

Cohen, M., Burkhart, R., Dosi, G., Egidi, M., Marengo, L., Warglien. and Winter, S. (1996) 'Routines and Other Recurring Action Patterns of Organizations: Contemporary Research Issues', Industrial and Corporate Change, 5: 653-698. 
Cowton, C. (1998) 'The Use of Secondary Data in Business Ethics Research', Journal of Business Ethics, 17: 423-434.

David, F. (2003) 'Strategic Management Case Writing: Suggestions After 20 Years of Experience', S.A.M. Advanced Management Journal, 68: 36-43.

De la Cruz Déniz-Déniz, M. and De Sáa-Pérez, P. (2003) 'A Resource-Based View of Corporate Responsiveness Toward Employees', Organization Studies, 24: 299-319.

Dierickx, I. and Cool, K. (1989) 'Asset Stock Accumulation and Sustainability of Competitive Advantage', Management Science, 35: 1504-1511.

Denzin, N. (1989) Interpretive Biography. Thousand Oaks: Sage Publications.

Denzin, N. and Lincoln, Y. (1994) Handbook of Qualitative Research. Newbury Park, CA: Sage.

Dewing, A. (1931) 'An Introduction to the Use of Cases', in C. Fraser (ed) A Case Method of Instruction. New York: McGraw-Hill.

Doz, Y. and Balchandani, A. (2003) 'Extending the 'Easy' Business Model: What Should Easygroup Do Next?', Case Reference: 303-093-1: INSEAD.

Dutta, S., Zbaracki, M. and Bergen, M. (2003) 'Pricing Process as a Capability: A ResourceBased Perspective', Strategic Management Journal, 24: 615-630.

Easton, G. (1992) Learning from Case Studies (2nd ed). New York: Prentice Hall.

Edge, A. and Coleman D. (1986) The Guide to Case Analysis and Reporting (3rd ed). Hawaii: System Logistics Inc.

Eisenhardt, K. (1989) 'Building Theories from Case Study Research?', Academy of Management Review, 14: 532-550.

Eisenhardt, K. and J. Martin (2000) 'Dynamic Capabilities: What are they?', Strategic Management Journal, 21:1105-1121. 
Feldman, M. and Pentland, B. (2003) 'Reconceptualizing Organizational Routines as a Source of Flexibility and Change', Administration Science Quarterly, 48: 94-118.

Frankfort-Nachmias, C. and Nachmias, D. (1996) Research Methods in the Social Sciences (5th ed). London: Arnold.

Garvin, D. (2007) 'Teaching Executives and Teaching MBAs: Reflections on the Case Method', Academy of Management Learning and Education, 6: 364-374.

Gibbert, M., Ruigrok, W. and Wicki, B. (2008) 'What Passes as a Rigorous Case Study?', Strategic Management Journal, 29: 1265-1274.

Ginsberg, A. (1984) 'Operationalizing Organizational Strategy: Toward an Integrative Framework', Academy of Management Review, 9: 548-557.

Greiner, L., Bhambri, A. and Cummings, T. (2003) 'Searching for a Strategy to Teach Strategy', Academy of Management Learning and Education, 2: 402-420.

Guba, E. and Lincoln, Y. (1994) 'Competing Paradigms in Qualitative Research', in N. Denzin and Y. Lincoln (eds) Handbook of Qualitative Research. Newbury Park, CA: Sage.

Gummesson, E. (1991) Qualitative Methods in Management Research. Newbury Park, CA: Sage.

Hakim, C. (1982) Secondary Analysis in Social Research. Boston: George Allen and Unwin. Harris, R. (2003) 'The Case Against Cases'. Accessed October 11 2006, from http://www.cfoeurope.com/displaystory.cfm/1777470/1_print.

Hartman, E. M. (2006) 'Can We Teach Character? An Aristotelian Answer', Academy of Management Learning and Education, 5: 68-81

Heath, J. (2002) Teaching and Writing Case Studies: A Practical Guide. Cranfield, UK: ecch UK Registered Office Publications.

Helfat, C. and Peteraf, M. (2003) 'The Dynamic Resource-Based View: Capability Lifecycles', Strategic Management Journal, 24: 997-1010. 
Heugens, P. and Mol, M. (2005) 'So You Call That Research? Mending Methodological Biases in Strategy and Organization Departments of Top Business Schools', Strategic Organization, 3: 117-128.

Hoffman, V., Trautmann, T. and Hamprecht, J. (2009) 'Regulatory Uncertainty: A Reason to Postpone Investments? Not Necessarily', Journal of Management Studies, 46: 1227-1253.

Hoque, Z. (2006) Methodological Issues in Accounting Research: Theories and Methods. London: Spiramus Press.

Huff, A, and Jenkins, M. (2002) Mapping Strategic Knowledge. Sage: London.

Jauch, L., Osborn, R. and Martin, T. (1980) 'Structured Content Analysis of Cases: A Complementary Method', Academy of Management Review, 5: 517-525.

Jennings, D. (1997) 'Researching and Writing Strategic Management Cases: A Systems View', Management Decision, 35: 100-105.

Kieser, A. (1994) 'Why Organization Theory Needs Historical Analyses - and How This Should be Performed?', Organization Science, 5: 608-620.

Klassen, R. and Menor, L. (2007) 'The Process Management Triangle: An Empirical Investigation of Process Trade-Offs', Journal of Operations Management, 25: 1015-1034.

Langley, A. (1989) 'In Search of Rationality: The Purposes Behind the Use of Formal Analysis in Organizations', Administrative Science Quarterly, 34: 598-631.

Larsson, R. (1993) 'Case Survey Methodology: Quantitative Analysis of Patterns Across Case Studies', Academy of Management Journal, 36: 1515-1546.

Larsson, R. and Finkelstein, S. (1999) 'Integrating Strategic, Organizational and Human Resource Perspectives on Mergers and Acquisitions: A Case Survey of Synergy Realization', Organization Science, 10: 1-26.

Larsson, R. and Lubatkin, M. (2001) 'Achieving Acculturation in Mergers and Acquisitions: An International Case Survey', Human Relations, 54: 1573-1607. 
Lawrence, P. (1953) 'The Preparation of Case Material', in K. Andrews (ed) The Case Method of Teaching Human Relations and Administrations. Cambridge, MA: Harvard University Press.

Leonard-Barton, D. (1992) 'Core Capabilities and Core Rigidities: A Paradox in Managing New Product Development', Strategic Management Journal, 13: 111-125.

Levitas, E. and Chi, T. (2002) 'Rethinking Rouse and Daellenbach's Rethinking: Isolating vs. Testing for Sources of Sustainable Competitive Advantage', Strategic Management Journal, 23: 957-962.

Liang, N. and Wang, J. (2004) 'Implicit Mental Models in Teaching Cases: An Empirical Study of Popular MBA Cases in The United States and China', Academy of Management Learning and Education, 3: 397-413.

Lincoln, Y. and Guba, E. (1985) Naturalistic Inquiry. Beverly Hills: Sage.

Lippman, S. and Rumelt, R. (1982) 'Uncertain Imitability: An Analysis of Interfirm Differences in Efficiency Under Competition', The Bell Journal of Economics, 13: 418-438. Lockett, A. and Thompson, S. (2001) 'The Resource-Based View and Economics', Journal of Management, 27: 723-754.

Lyford C., Beierlein, J. and Harling, K. (2000) 'Scholarship and Decision Cases: Pedagogy and Standards for Publication', International Food and Agribusiness Management Review, 3: $369-379$

McGaughey, S. and Liesch, P. (2002) 'The Global Sports-Media Nexus: Reflections on the “Super League Saga” in Australia', Journal of Management Studies, 39: 383-416.

McGrath, J. (1981) 'Dilemmatics: The Study of Research Choices and Dilemmas', American Behavioral Scientist, 25: 179-210.

McKelvey, B. (1997) 'Quasi-natural Organization Science', Organization Science, 8: 352380. 
Makadok, R. (2001) 'Toward a Synthesis of the Resource-Based and Dynamic-Capability Views of Rent Creation', Strategic Management Journal, 22: 387-401.

Maritan, C. (2001) 'Capital Investment as Investing in Organizational Capabilities: An Empirically Grounded Process Model', Academy of Management Journal, 44: 513-531.

Mauffette-Leenders, L., Erskine, J. and Leenders, M. (1997) Learning With Cases. Ontario: Richard Ivey School of Business.

Miller, D. (1994) 'What Happens After Success: The Perils of Excellence', Journal of Management Studies, 31: 325-358.

Miller, D. (2003) 'An Asymmetry-Based View of Advantage: Towards an Attainable Sustainability', Strategic Management Journal, 24: 961-976.

Miller, D. and Friesen, P. (1977) 'Strategy-Making in Context: Ten Empirical Archetypes', Journal of Management Studies, 14: 253-280.

Naumes, W. and Naumes, M. (1999) The Art and Craft of Case Writing. London: Sage.

Newbert S. (2007) 'Empirical Research on the Resource-Based View of the Firm: An Assessment and Suggestions for Future Research', Strategic Management Journal, 28: 121146.

Newbert S. (2008) 'Value, Rareness, Competitive Advantage, and Performance: A Conceptual-Level Empirical Investigation of the Resource-Based View of the Firm', Strategic Management Journal, 29: 745-768.

Nonaka, I. (1991) 'The Knowledge-Creating Company', Harvard Business Review, 69: 96104.

Peng, M. (2001) The Resource-Based View and International Business', Journal of Management, 27: 803-829.

Pitt, D. (1972) Using Historical Sources in Anthropology and Sociology. New York: Holt, Rinehart and Winston. 
Porter, M. (1996) 'What is Strategy?', Harvard Business Review, Nov-Dec:61-78.

Priem, R. and Butler, J. (2001) 'Is the Resource-Based 'View' a Useful Perspective for Strategic Management Research?', Academy of Management Review, 26: 22-40.

Ragin, C (1989) The Comparative Method: Moving Beyond Qualitative and Quantitative Strategies. California: University of California Press.

Reeves, T., Ford, E., Duncan, W. and Ginter, P. (2005) 'Communication Clarity in Strategic Management Data Sources', Strategic Organization, 3: 243-278.

Regani, S. and Dutta, S. (2003) 'Easyjet: The 'Easy' Way To Succeed', Case Reference: 303193-1: ICMR Center for Management Research.

Reynolds, T. and Gutman, J. (1988) 'Laddering Theory, Method, Analysis and Interpretation', Journal of Advertising Research, 28: 11-31.

Rivkin, J. (2000) 'Imitation of Complex Strategies', Management Science, 46: 824-844.

Rogers, B. and Kumar, N. (2000) 'Easyjet: The Web's Favourite Airline', Case Reference: IMD-3-0873: International Institute for Management Development.

Rouse, M. and Daellenbach, U. (1999) 'Rethinking Research Methods for the ResourceBased Perspective: Isolating Sources of Sustainable Competitive Advantage', Strategic Management Journal, 20: 487-494.

Rouse, M. and Daellenbach, U. (2002) 'More Thinking on Research Methods for the Resource-Based Perspective', Strategic Management Journal, 23: 963-967.

Rousseau, D. and House, R. (1994) 'Meso-Organizational Behavior: Avoiding Three Fundamental Biases', Journal of Organizational Behavior, 1: 13-30.

Rynes, S. (2007) 'Getting on Board" with AMJ: Balancing Quality and Innovation in the Review Process, Academy of Management Journal, 49: 1097-1102.

Saxton, T. and Dollinger, M. (2004) 'Target Reputation and Appropriability: Picking and Deploying Resources in Acquisitions', Journal of Management, 30: 123-147. 
Seabright, M., Levinthal, D and Fichman, M. (1992) 'Role of Individual Attachments in the Dissolution of Interorganizational Relationships', Academy of Management Journal, 35: 122160.

Shah, S. and Corley, K. (2006) 'Building Better Theory by Bridging the QuantitativeQualitative Divide', Journal of Management Studies, 43: 1821-1835.

Sharma, S. and Vredenburg, H. (1998) 'Proactive Corporate Environmental Strategy and the Development of Competitively Valuable Organizational Capabilities', Strategic Management Journal, 19: 729-753.

Siggelkow, N. (2007) 'Persuasion with Case Studies', Academy of Management Journal, 50: 20-24.

Smith, H. (1975) Strategies of Social Research: The Methodological Imagination. Englewood Cliffs: Prentice-Hall.

Strauss, A. and Corbin, J. (1998) Basics of Qualitative Research, (2 ${ }^{\text {nd }}$ edition). Sage: London. Swiercz, P. and Ross, K. (2003) 'Rational, Human, Political, and Symbolic Text in Harvard Business School Cases: A Study of Structure and Content', Journal of Management Education, 27: 407-430.

Teece, D. (1986) 'Profiting from Technological Innovation', Research Policy, 15: 285-305.

Thorne, S. (1994) 'Secondary Analysis in Qualitative Research: Issues and Implications', in J. Morse (ed) Critical Issues in Qualitative Research Method, pp. 263-79. Thousand Oaks: Sage.

Tranfield, D. and Smith, S. (1998) 'The Strategic Regeneration of Manufacturing by Changing Routines', International Journal of Operations and Production Management, 18: $114-129$

Weick, K. (1979) The Social Psychology of Organizing. Reading, Mass: Addison-Wesley. 
Wernerfelt, B. (1995) 'The Resource-Based View of the Firm: Ten Years After', Strategic Management Journal, 16: 171-174.

Wright, P., Dunford, B. and Snell, S. (2001) 'Human Resources and the Resource Based View of the Firm', Journal of Management, 27: 701-721.

Yin, R. (1984) Case Study Research: Design and Methods. London: Sage.

Yin, R. (1994) Case Study Research: Design and Methods (2nd ed). London: Sage.

Yin, R. and Heald, K. (1975) 'Using the Case Survey Method to Analyze Policy Studies', Administrative Science Quarterly, 20: 371-381.

Young, M. (1989) 'Research Notes and Communications Sources of Competitive Data for the Management Strategist', Strategic Management Journal, 10: 285-293.

\section{Author Biographies}

Véronique Ambrosini is a professor of strategic management at Birmingham University Business School. Her research is conducted essentially within the resource-based and dynamic capability view of the firm. Véronique has published among others in Human Relations, Management Learning, Journal of Management Studies, International Journal of Management Reviews and the British Journal of Management. She is a co-editor of Advanced Strategic Management: A Multiple Perspective Approach. Address: Birmingham Business School, University House, University of Birmingham, Edgbaston, Birmingham B15 2TT, UK. [email: v.ambrosini@bham.ac.uk]

Cliff Bowman is a professor of strategic management at Cranfield School of Management. His research interests focus on the creation and capture of value and he has recently published in the Journal of Management Studies and the British Journal of Management. Address: Cranfield School of Management, Cranfield, Bedford MK43 0AL, UK. [email: cliff.bowman@cranfield.ac.uk]

Nardine Collier is a research officer in strategic management at Cranfield School of Management. Her current research interests include firm turnaround and the resource-based view of the firm. She has had articles published in Long Range Planning, International Journal of Management Reviews and British Journal of Management. Address: Cranfield 
School of Management, Cranfield, Bedford MK43 0AL, UK. [email: n.collier@cranfield.ac.uk] 